\title{
FATIGUE LIFE ANALYSIS AND OPTIMIZATION OF A PASSENGER CAR STEERING KNUCKLE UNDER OPERATING CONDITIONS
}

\author{
V. Sivananth ${ }^{1}$ and S.Vijayarangan ${ }^{2}$ \\ ${ }^{1}$ Department of Automobile Engineering \\ Dr. Mahalingham College of Engineering and Technology \\ Pollachi - 642003, Tamilnadu, India. \\ Email: vsivananth@gmail.com \\ Phone: 9944328963; Fax: +91 4259 - 236030
}

\begin{abstract}
This paper presents a methodology for analyzing the multiaxial loads acting on a steering knuckle under operating conditions. The knuckle is a critical structural part which connects the wheel in a car to the steering and suspension system. Computeraided modeling and analysis were carried out on the knuckle, and the results were compared for conventional and metal matrix composites (MMC) with ANSYS software. The simulation showed that the steering-arm region failed under cyclic load conditions. Accordingly, the knuckle was optimized with a genetic algorithm and a modified design was proposed. Steering knuckles were fabricated from three different materials: ductile iron, LM 6 alloy and MMC with a modified design were experimentally tested in the steering-arm region to evaluate the fatigue life. Simulation results showed that the fatigue life of the MMC knuckle was $1.946 \mathrm{E}+06$ fatigue cycles after optimization whereas experimental results showed $1.20 \mathrm{E}+06$ cycles. Knuckle weight reduction of $60 \%$ was achieved by replacing ductile iron with MMC. Hence it is recommended to use MMC steering knuckles in automobiles.
\end{abstract}

Keywords: Steering knuckle; multiaxial force; fatigue life; optimization; MMC.

\section{INTRODUCTION}

Metal matrix composites (MMC) have the potential to meet the design requirements of the automobile industry with significant weight saving and a high strength-to-weight ratio [1-3]. Recent developments in aluminum-based MMC make it the ideal candidate to replace heavier materials like iron and steel in the car for weight reduction [4]. The suspension of modern vehicles needs to satisfy a number of requirements such as loading, driving condition and type of road surface. The steering knuckle is one of the main components used in the McPherson suspension system (Figure 1) in automobiles subjected to millions of varying stress cycles during their life [5]. This demands the thorough study and understanding of the behavior of the steering knuckle under operating conditions. Multi-body simulation was used to calculate the load time history regarding the connection points of the knuckle on the suspension system [6]. Performances of forged steel and cast aluminum knuckles were studied in the light of their manufacturing processes [7].The results showed forged components have better resistance to cyclic load. Fatigue life evaluation of a structure under multiaxial load condition relies on stress-strain distribution [8-12]. Real-time fracture characteristics of a ductile iron knuckle were studied by Triantafyllidis et al. [13]. They found that the 
steering-arm portion undergoes repeated bending loads during the vehicle's movement, and it leads to failure because of bending fatigue condition. MMC with ceramic TiC reinforcing particles show good mechanical strength, Vijayarangan et al. proved through simulations and experiments that composite knuckles could safely replace spheroidal graphite iron [14]. Sivananth et al. studied the effect of titanium carbide particulates in aluminum matrix and reported that the fatigue and impact behavior improved compared with conventional materials [7]. Geometry and size optimization of steering knuckles reduce the production cost and decrease the weight, as shown by Jahala [15]. The fatigue life of the knuckle was determined with a reliability-based design optimization approach [16].The present study identifies the failure region of the knuckle under operating conditions and optimizes the same for three materials: SG iron, LM 6 alloy and MMC. After optimization, the fatigue life of the knuckle is compared by means of finite element analysis and experimental testing.

\section{MULTIAXIAL LOAD ANALYSIS}

A steering knuckle located in a McPherson suspension system was attached to a strut tube at the top and the lower arm was placed at the bottom tie-rod on the side, as shown in Figure 1. The directions of forces acting on it varied with load cases and the vehicle specification. Dimensions and load cases for the analysis of knuckles were bought from M/s. Sakthi Auto Components Ltd, India, a leading manufacturer. The present study considered three important driving load cases of a passenger car: acceleration, braking and cornering. Analysis showed that in each load case 12 force components simultaneously delivered a load to the knuckle in different directions. The details of multiaxial loads obtained from vehicle manufacturers are shown in Table 1.

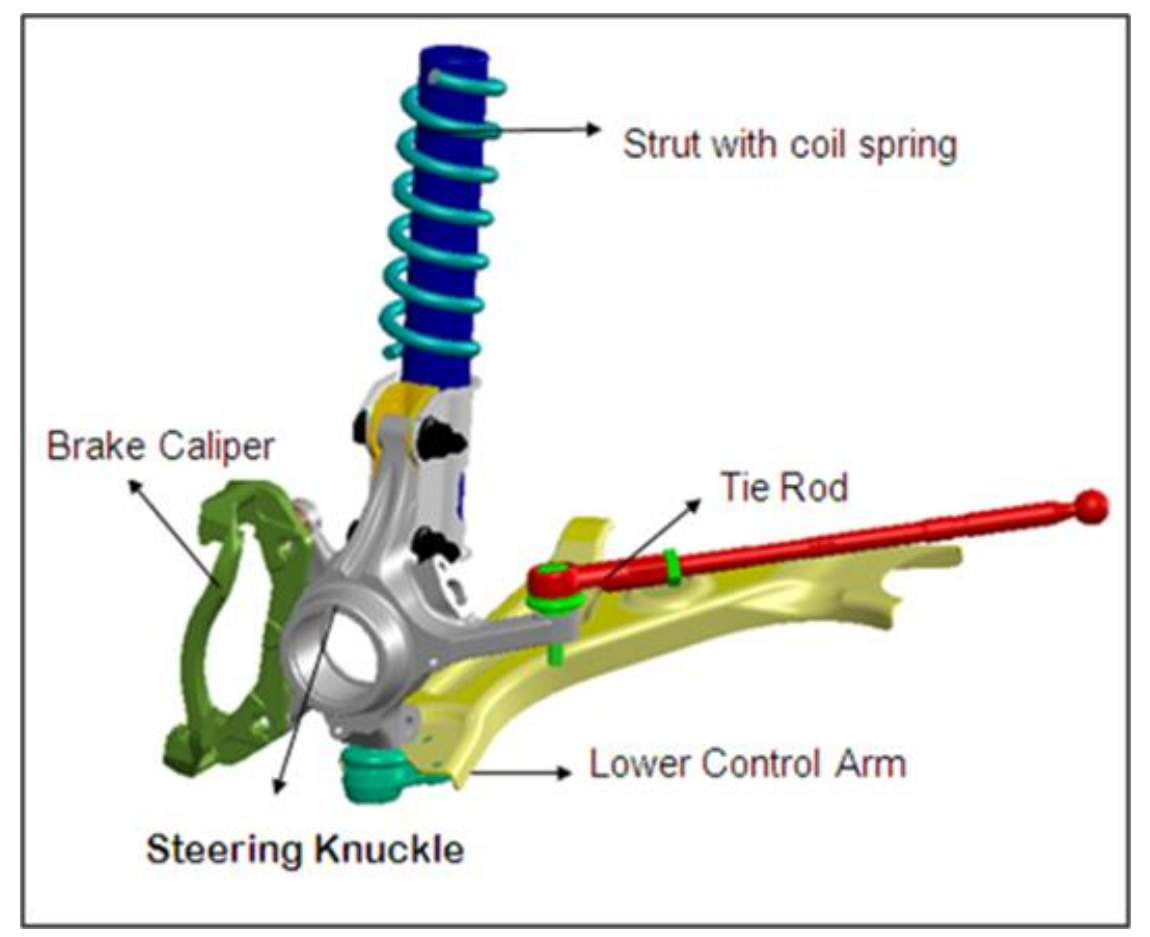

Figure 1. Steering knuckle location in McPherson suspension system. 
Table 1. Multiaxial loads.

\begin{tabular}{lcrrr}
\hline Driving Condition & Location & \multicolumn{3}{c}{ Multiaxial Loads (N) } \\
\cline { 3 - 5 } & & \multicolumn{1}{c}{$X$} & \multicolumn{1}{c}{$Z$} \\
\hline $0.8 \mathrm{~g}$ cornering & & -350 & -250 & -5650 \\
0.5 acceleration & \multirow{2}{*}{ Strut } & 90 & -2080 & 3230 \\
$1.1 \mathrm{~g}$ braking & & 1600 & -1680 & -4370 \\
\hline $0.8 \mathrm{~g}$ cornering & & -100 & -630 & 150 \\
0.5 acceleration & Tie-rod & 120 & 1040 & 80 \\
$1.1 \mathrm{~g}$ braking & & 50 & 460 & -80 \\
\hline $0.8 \mathrm{~g}$ cornering & & -60 & 6260 & 7340 \\
0.5 acceleration & Hub & -1690 & 50 & 2930 \\
$1.1 \mathrm{~g}$ braking & & 6730 & -140 & 5570 \\
\hline $0.8 \mathrm{~g}$ cornering & \multirow{2}{*}{ Lower } & 310 & -4200 & 250 \\
0.5 acceleration & arm & 1390 & 50 & 80 \\
$1.1 \mathrm{~g}$ braking & & -5450 & 1370 & -550 \\
\hline
\end{tabular}

\section{Modeling and Analysis of Knuckle}

The dimensions used to create the knuckle model were taken from a passenger car. The knuckle shown in Figure 2 (a) was developed with NX CAD software. A finite-element model was created with the preprocessing tool Hypermesh 12. The model was divided into 70,526 elements and 1, 15,042 nodes. The effects of load on the knuckle during cornering, acceleration and braking were analyzed and discussed. Statistical analysis was performed with ANSYS software. The loads shown in Table 1 were applied in the model as shown in Figure 2 (b). The material properties shown in Table 2 were taken from the experimental work reported by Sivananth et al. [7].
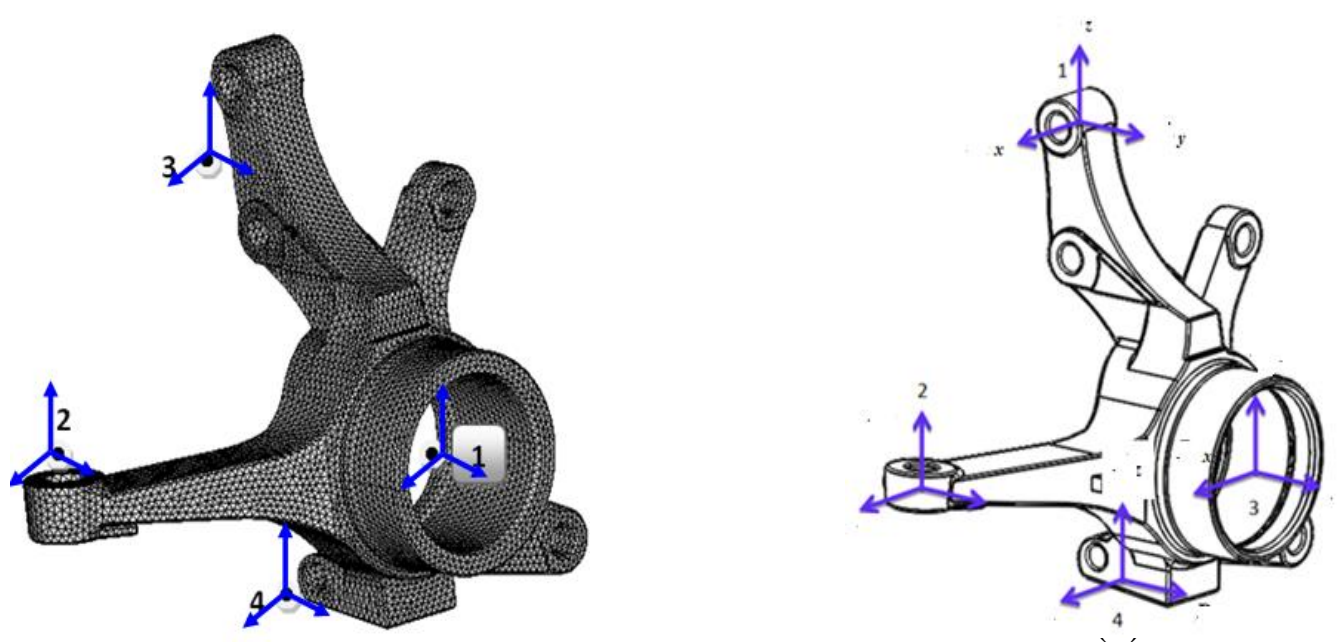

Figure 2. Steering knuckle (a) finite-element model; (b) multiaxial load directions. 
Table 2. Material properties used for analysis.

\begin{tabular}{lcccc}
\hline \multicolumn{1}{c}{ Material } & UTS (MPa) & YS (MPa) & E [17] & Fatigue Strength (MPa) \\
\hline LM 6 alloy & 254 & 187 & 73 & 133 \\
Al-10\% TiC & 281 & 201 & 79 & 194 \\
Al-12\% TiC & 289 & 213 & 84 & 214 \\
Al-15\% TiC & 323 & 265 & 87 & 248 \\
Ductile iron & 418 & 276 & 170 & 180 \\
\hline
\end{tabular}

\section{Simulation of Uniaxial Load: Fatigue Analysis}

The uniaxial force required to create a bending load on the steering arm region was calculated as follows for a passenger car. The total weight of the passenger car considered for this study was $1166 \mathrm{~kg}$. The weight distribution ratio between the front and rear axle as was taken as 60: 40. Therefore, the force acting on each wheel in the front axle was $3500 \mathrm{~N}$. Figure 3(a) shows the steering torque direction acting on the ball joint of the knuckle to steer one wheel. With a friction coefficient of 0.8 for a dry road surface, $2.8 \mathrm{kN}$ force was required to steer one wheel to overcome the frictional force $\left(F_{f}\right)$, as shown in Figure 3 (a). Steering-arm fatigue analysis was carried out with the stress life approach in ANSYS software to determine the fatigue life and damage of the knuckle under the $2.8 \mathrm{kN}$ cyclic load. The statistical analysis results showed the von Mises stress of the knuckle was critical in the steering-arm region and led to failure. Therefore, fatigue analysis was performed by applying force and boundary conditions as shown in Figure 3 (b). To determine fatigue life and damage, the design life of 1E+06 cycles was fixed as reference in this study.

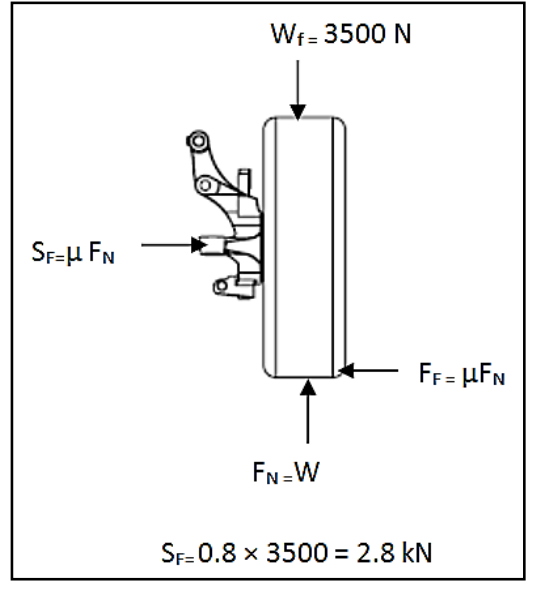

(a)

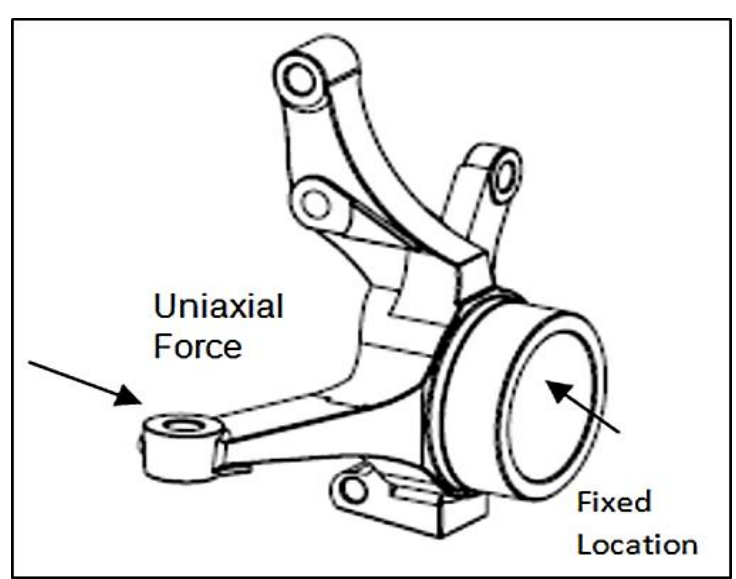

(b)

Figure 3. (a) Steering-arm load calculation; (b) fatigue analysis at steering arm.

\section{OPTIMIZATION OF KNUCKLE IN STEERING-ARM REGION}

Optimization is a technique for finding an optimal solution for the objective function under given constraints. The fatigue analysis showed that the steering-arm portion of the knuckle failed when it experienced cyclic load as shown in Figure 4(a).The steering arm was 
treated as a cantilever beam for optimization and load was applied at the free end as shown in Figure 4(b-c). The genetic algorithm (GA) is a method for solving both constrained and unconstrained optimization problems that are based on natural selection, the process that drives biological evolution [13]. Hence it was safe to optimize the cross-section of the knuckle at that region with cantilever approximation. In this study, a tailor-made code was developed from MATLAB to solve Eqs. (1-6) with a GA. The objective function shown in Eqs. (1) and (2) represents the fitness function to be optimized. To minimize the stress and deflection for $2.8 \mathrm{kN}$ force, the constraints were formulated. During optimization, the maximum and minimum limits shown in Eqs. (3-4) of the beam cross-section are significant in terms of obtaining a solution. The weight of the cantilever beam varies depending on the following parameters: dimension, mass and density. The length of the beam was taken from the knuckle design as $80 \mathrm{~mm}$ and mass of the beam not more than $20 \%$ of the existing one to formulate in Eqs. (5-6). This made the process more effective without increasing the weight while approaching the optimized solution. The moment of inertia of the beam with the existing cross-section was taken as a mass constraint to ensure the obtained dimensions were always greater than the existing ones.
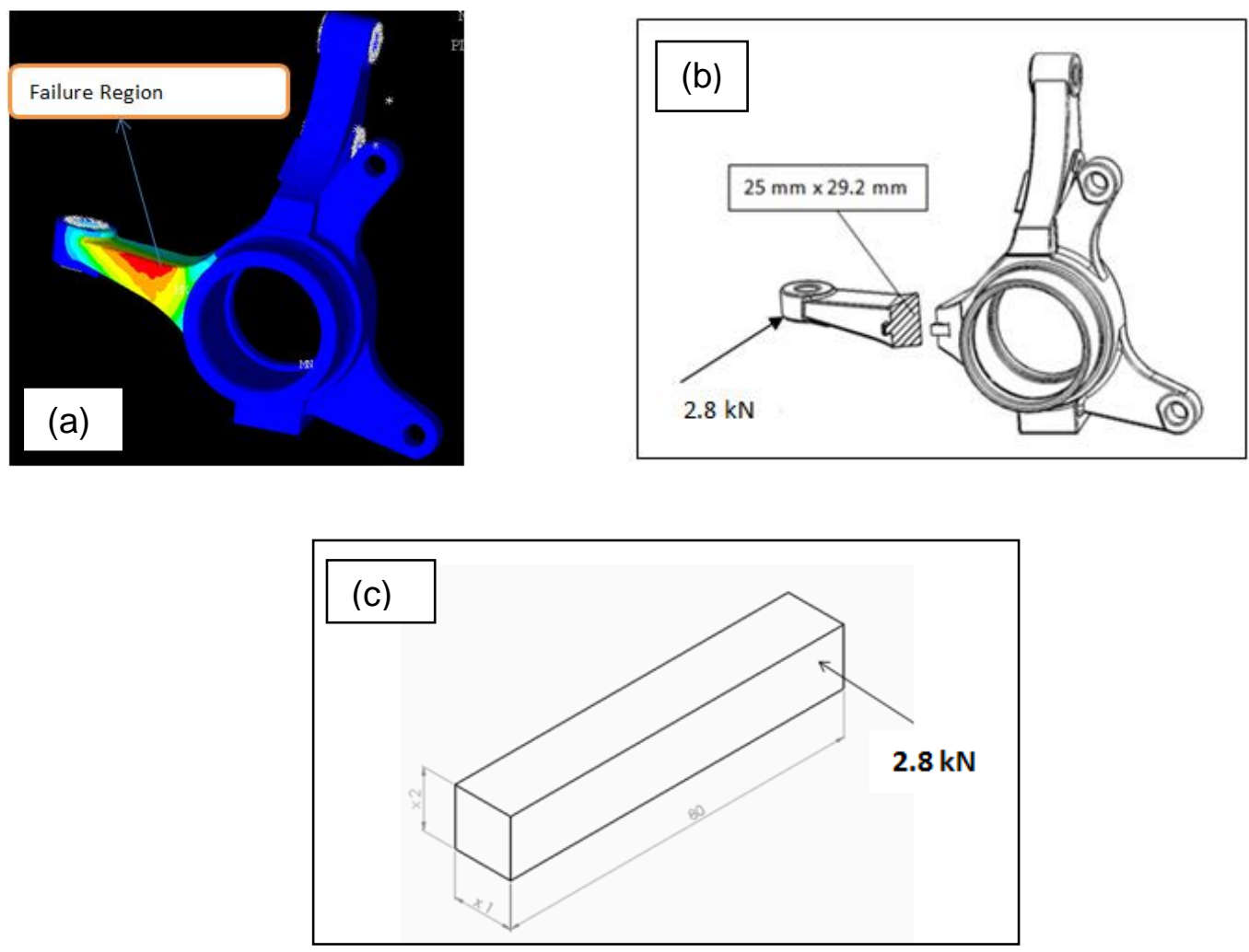

Figure 4. (a) Steering arm failure (b) cross -section at failure region (c) steering arm considered as cantilever beam.

\section{Objective Function}

$$
\begin{aligned}
& f\left(x_{1} x_{2}\right)=\frac{W L^{3}}{3 E I} \\
& g\left(x_{1} x_{2}\right)=\frac{M_{b} y}{I}
\end{aligned}
$$




\section{Cross-section Constraint}

Minimum Limit:

$$
x_{1 \max }=30 \mathrm{~mm} ; x_{2 \min }=25 \mathrm{~mm}
$$

Maximum Limit

$$
x_{1 \max }=35 \mathrm{~mm} ; x_{2 \min }=29 \mathrm{~mm}
$$

\section{Mass Constraint}

$$
\begin{gathered}
x_{1} x_{2} L \rho \leq m \\
\frac{x_{1} x_{2}^{3}}{12} \geq I
\end{gathered}
$$

\section{FABRICATION AND TESTING OF STEERING KNUCKLE}

Steering knuckles made of ductile iron, LM 6 alloy and MMC were fabricated by the casting method. LM 6 aluminum alloy was used as a matrix with 15 wt. \% titanium carbide particulates as reinforcement to fabricate an MMC knuckle. To make a pattern to cast the knuckle, dimensional details of the steering knuckle were taken from a passenger car which was fitted with a McPherson suspension system. The wheel movement of the car was controlled through a ball joint which connected the knuckle and tie-rod when force was applied on the steering wheel.

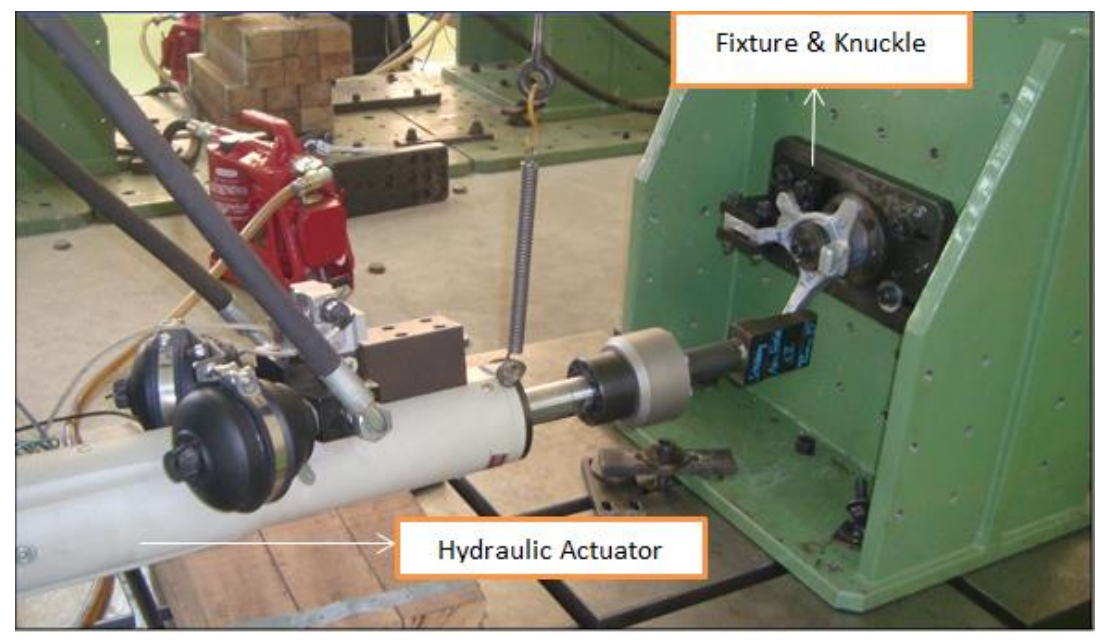

Figure 5. Steering arm fatigue test.

A hydraulic actuator supplied by Instron Structural Systems, Germany was used in this work for testing. A fixture set up as shown in Figure 5 was used to simulate the load transfer of a real case. The fixture accommodated the knuckle in such a way that the steering arm portion could be tested for fatigue life. The actuator used for testing could produce a minimum force of $0.5 \mathrm{kN}$ and a maximum force of $25 \mathrm{kN}$ according to requirements. A fatigue test was conducted on the knuckle in tension-compression mode 
with a starting load of $0.5 \mathrm{kN}$. Then the load was gradually increased up to $2.8 \mathrm{kN}$ with a load increment of $0.5 \mathrm{kN}$ between every $2 \times 10^{5}$ cycles. The stress ratio of $\mathrm{R}=-1$ and frequency of $15 \mathrm{~Hz}$ were constant for all load conditions.

\section{RESULTS AND DISCUSSION}

\section{Optimization Results}

The performances of the knuckle simulated in the ANSYS environment are compared in Figure 6. In this study of the braking load case, the von Mises stress developed in the knuckle was $78.79 \mathrm{MPa}$ in $1.1 \mathrm{~g}$ braking, the highest found. The stress developed in the knuckle was $26.53 \mathrm{MPa}$ and $34.8 \mathrm{MPa}$ for acceleration and cornering. The stress obtained for the considered material compared with yield strength listed in Table 3 showed that the stress values were well below the yield limit. The red-colored stress shown in Figure 7 indicates that the steering-arm portion of the knuckle is sensitive and it required more study when a cyclic load was applied. Table 3 shows that before optimization the existing cross-section of $(25 \times 29.2)$ of an MMC beam with $15 \%$ reinforcement experiences a bending stress of $131.5 \mathrm{~N} / \mathrm{mm}^{2}$ and $0.258 \mathrm{~mm}$ deflection for a load of $2.8 \mathrm{kN}$. After optimization, the results indicated that the MMC cantilever beam requires a cross-section of $(30 \times 31)$ under the same load. The steering-arm portion could deflect $0.13 \mathrm{~mm}$ to produce a maximum of $83.05 \mathrm{~N} / \mathrm{mm}^{2}$ bending stress. In Table 4, the bending stress and deflection are reduced by the optimization process for the considered materials. The optimized cross-section was implemented in the knuckle steering-arm region to improve the strength of the knuckle. The details are shown in Figure 8.

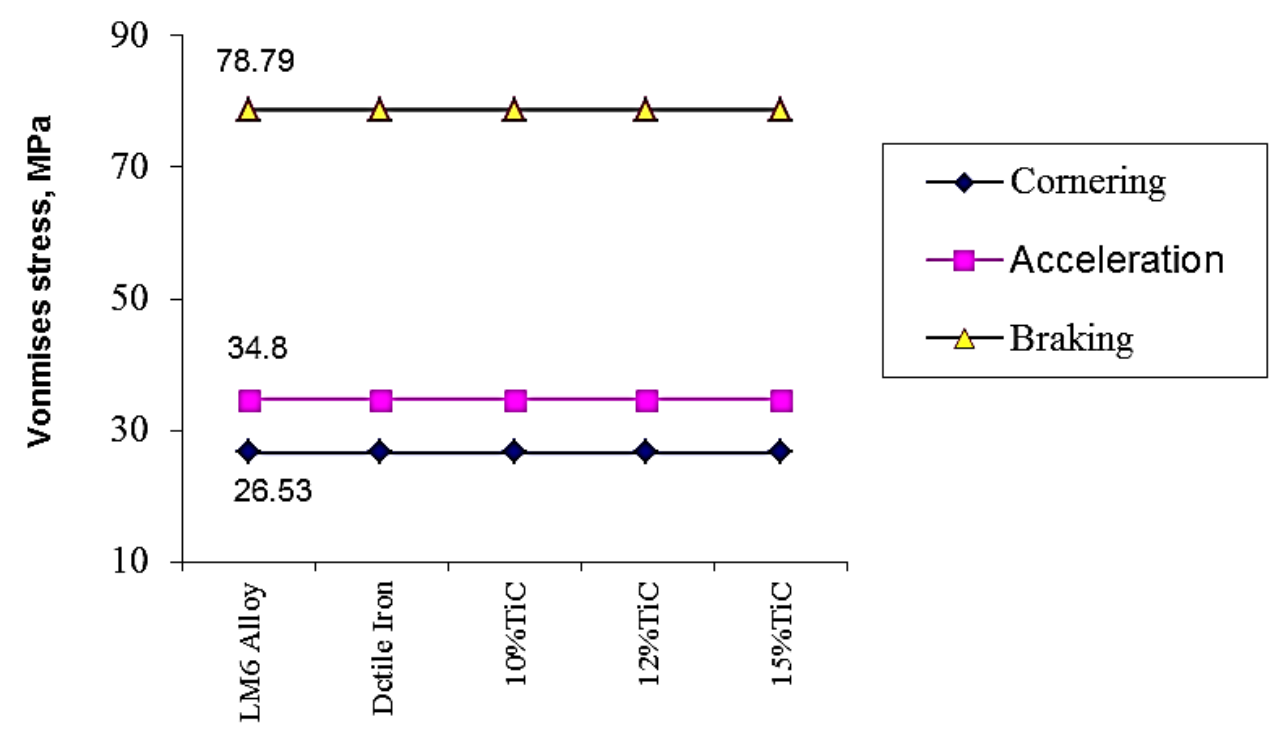

Materials Considered

Figure 6. Von Mises stress vs. materials. 


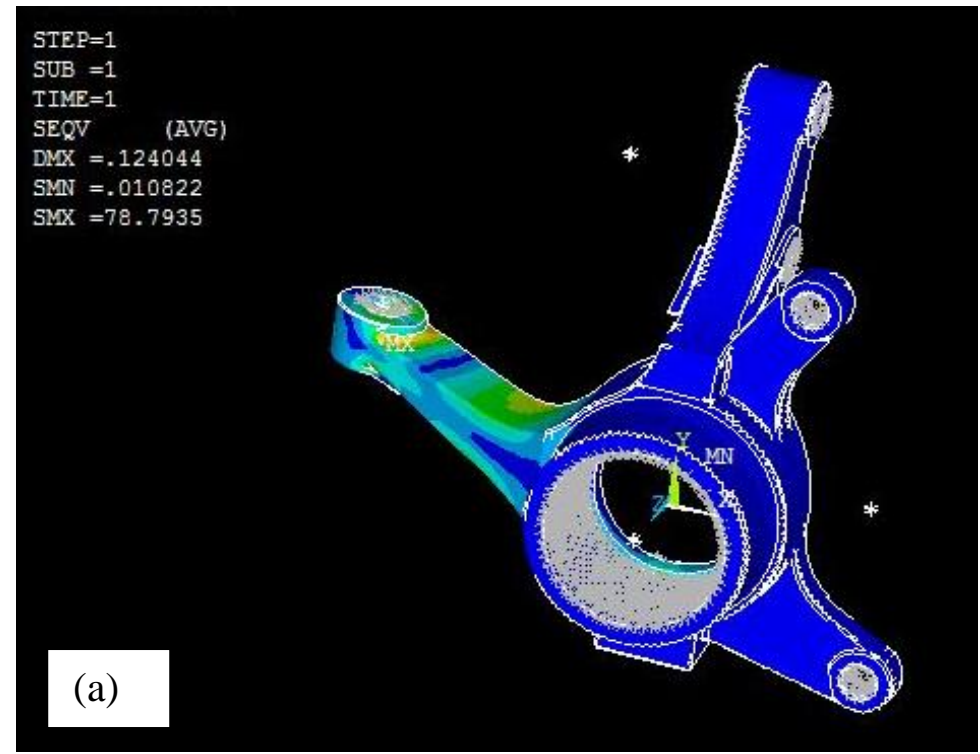

Figure 7. von Mises stress contour plot for $15 \mathrm{wt} . \% \mathrm{TiC}$.

Table 3. Steering arm cross-section before optimization.

\begin{tabular}{lccc}
\hline Parameters & LM 6 alloy & Ductile iron & MMC 15\% TiC \\
\hline Maximum bending stress, N/mm & 131.5 & 131.5 & 131.5 \\
Maximum deflection, mm & 0.32 & 0.13 & 0.258 \\
Cross-section dimensions, $\mathrm{mm}$ & $25 \times 29.2$ & $25 \times 29.2$ & $25 \times 29.2$ \\
\hline
\end{tabular}

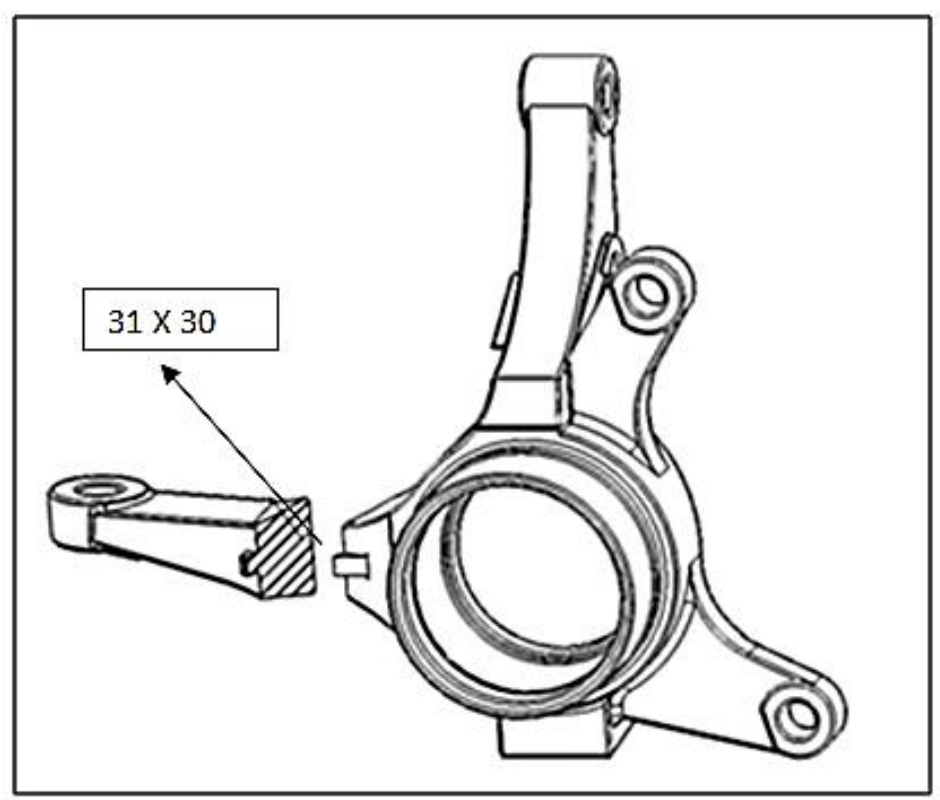

Figure 8. Cross-section dimensions implemented in steering-arm critical region. 
Table 4. Steering arm cross-section after optimization.

\begin{tabular}{lccc}
\hline Parameters & LM 6 alloy & Ductile iron & MMC 15\% TiC \\
\hline Maximum bending stress, N/mm & 81.09 & 111.6 & 83.05 \\
Maximum deflection, mm & 0.15 & 0.10 & 0.13 \\
Cross-section dimensions, mm & $31 \times 30$ & $26.7 \times 30$ & $31 \times 30$ \\
\hline
\end{tabular}

\section{Fatigue Analysis}

Fatigue life comparison for the three materials before and after optimization is shown in Figure 9. The results show that the fatigue life of the MMC knuckles survived a minimum of $0.989 \times 10^{6}$ cycles and a maximum of $1.65 \times 10^{6}$ cycles before optimization. In Figure 9, after the optimization, the life period of the MMC knuckles has increased and varies from $1.16 \times 10^{6}$ cycles to $1.95 \times 10^{6}$ cycles. For ductile iron and LM 6 aluminum alloy, the life is shorter than the MMC, in agreement with the published literature [9].

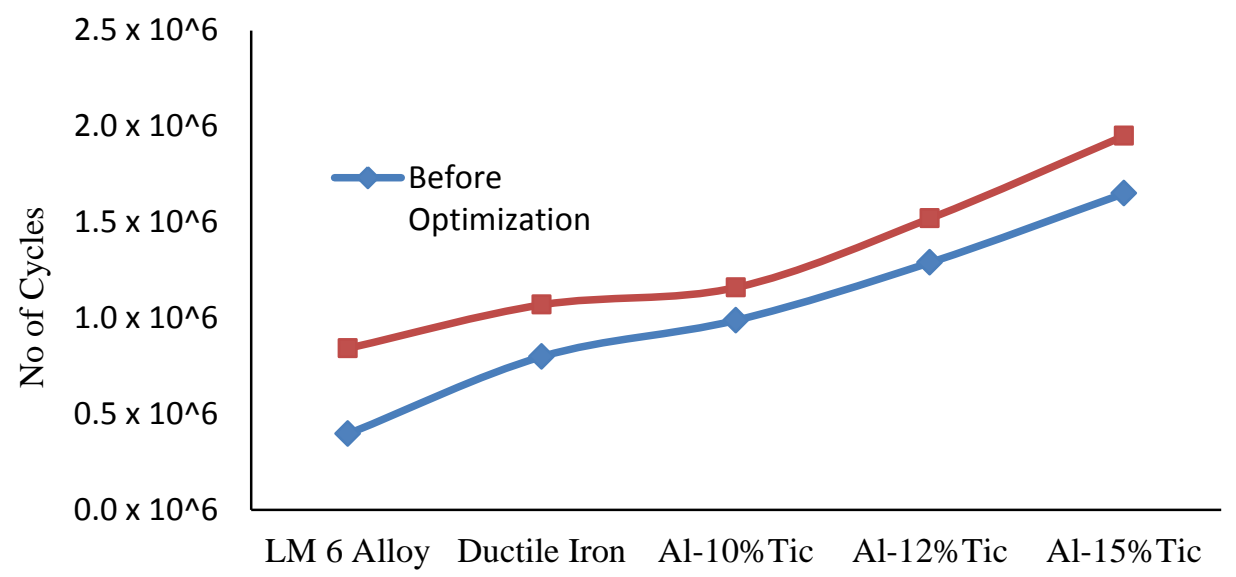

Figure 9. Fatigue life comparisons before and after optimization.

The contour plot for $15 \%$ reinforced TiC MMC before optimization is shown in Figure 10(a). It shows that the knuckle life is a minimum $1.65 \times 10^{6}$ cycles in the steering-arm region and a maximum $1.2 \times 10^{7}$ cycles for other portions of the knuckle. For the MMC knuckle with $15 \% \mathrm{TiC}$, the obtained life of $1.95 \times 10^{6}$ is shown in Figure 10(b). The knuckle can survive a minimum of $110^{6}$ cycles to achieve the required life. This is possible only when the damage value is not more than one. Figure 11 shows damage value of less than one for $12 \% \mathrm{TiC}$ and $15 \% \mathrm{TiC}$ reinforcement knuckles. The other materials, ductile iron, LM 6 matrix alloy and 10\% TiC MMC, failed. The damage comparison presented in Figure 11 suggests that except for the LM6 matrix alloy the damage values for all the materials were less than one after optimization. A damage contour plot for $15 \%$ TiC MMC before optimization is shown in Figure 12(a) and indicates that the crack initiation spot was present on the edge and increased the damage. This is in agreement with the findings of Triantafyllidis et al. [7]. However, post optimization the location changed from the edge to the surface, as shown is Figure 12(b). 


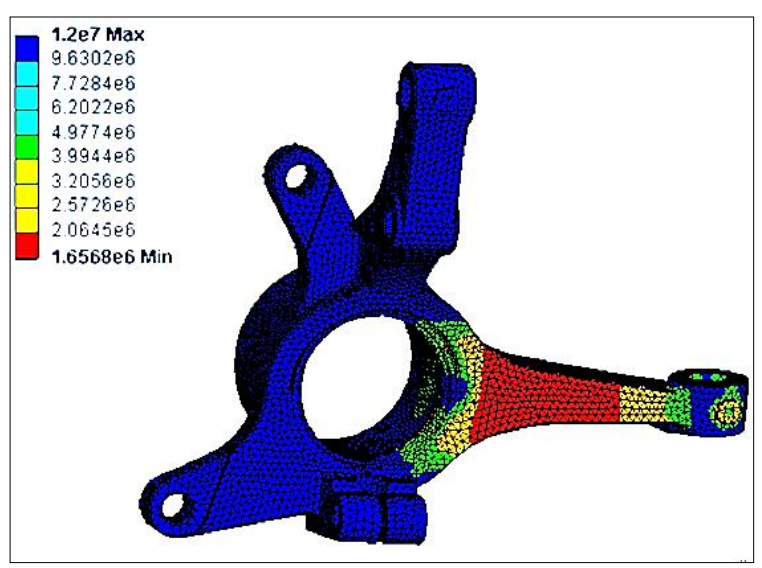

(a)

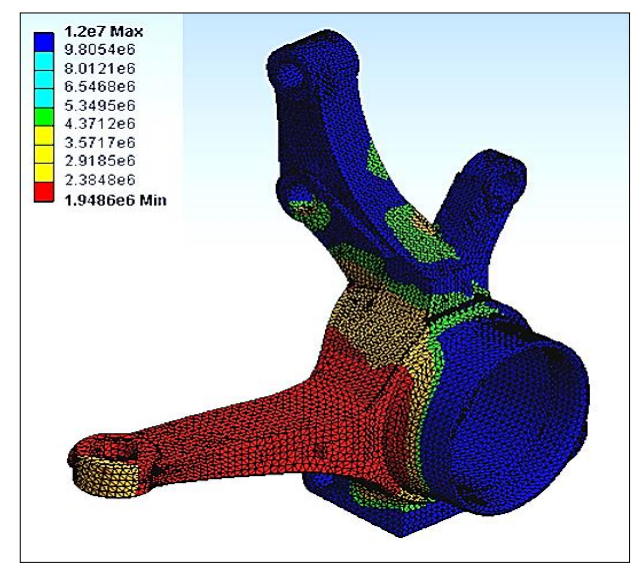

(b)

Figure 10. Fatigue life of 15 wt. \% TiC (a) before optimization (b) after optimization.

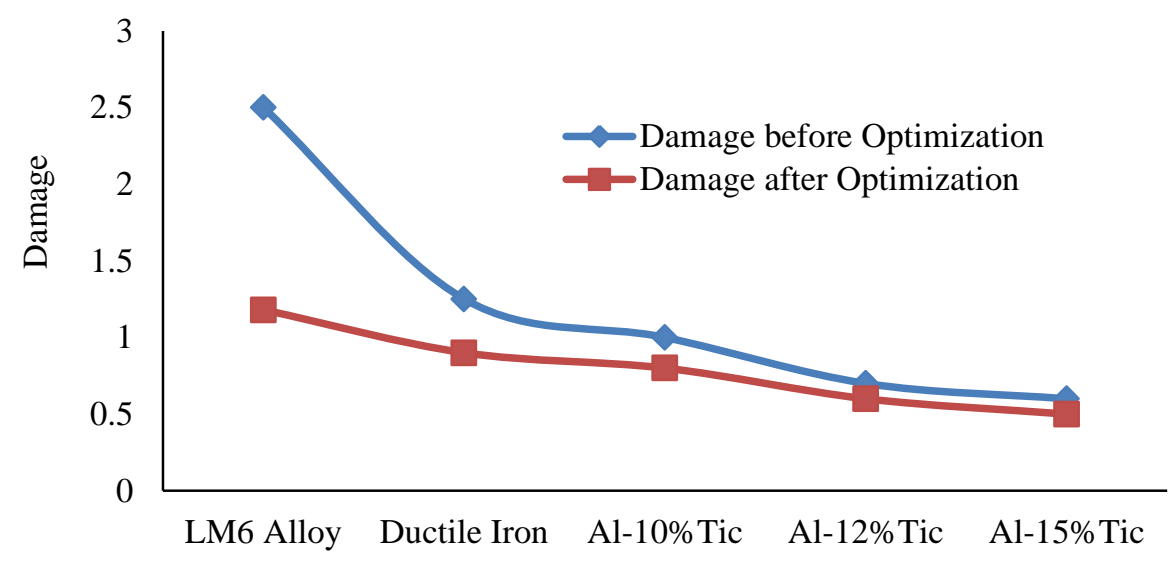

Figure 11. Damage comparisons before and after optimization

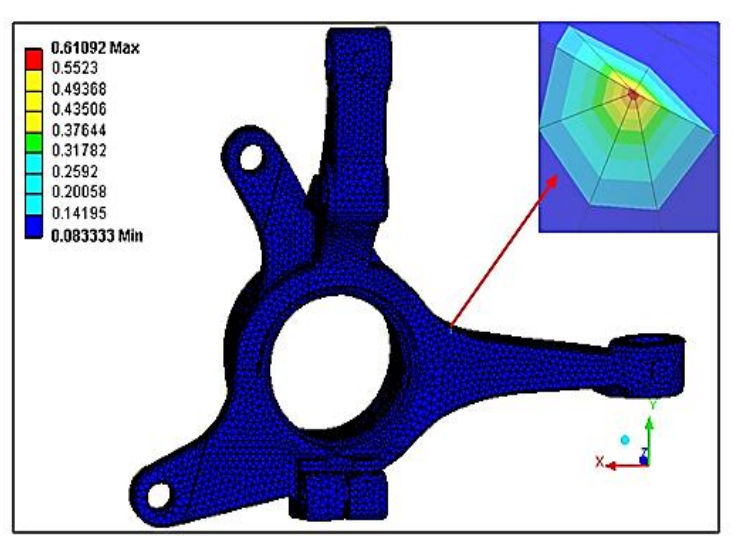

(a)

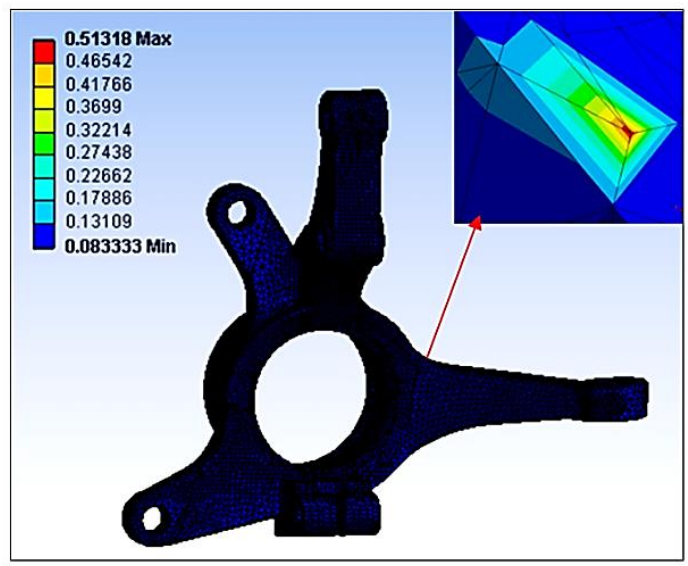

(b)

Figure 12. Damage to $15 \%$ TiC reinforced MMC (a) before optimization (b) after optimization. 


\section{Experimental Fatigue Results}

The fabricated composite knuckle with 15 wt. \% TiC withstands a $2.8 \mathrm{kN}$ load up to $1.2 \times 10^{6}$ cycles without any failure, and the details are summarized in Table 5. The fatigue strength of the LM 6 alloy without reinforcement is only $5.36 \times 10^{5}$ cycles at $2.8 \mathrm{kN}$. This is owed to the absence of a strong crack-arresting mechanism in LM6 alloy which resists crack development during cyclic loading [7]. Therefore, the stress concentration increases and reduces the fatigue performance of the LM 6 aluminum alloy. Furthermore, if its primary silicon particles have a coarse morphology, it can resist the slip and dislocation of the mechanism only, to a certain extent, and then it becomes cracked and reduces the life of the knuckle. This could be the reason for the lower load-bearing capacity of the LM 6 alloy knuckle compared with the MMC knuckle [14]. The ductile iron knuckle experiences $9.37 \times 10^{6}$ fatigue cycles before it fails because of brittle transition. The spheroidal graphite nodules present in it rupture and connect the crack propagation [13]. This reduces the fatigue life compared with the MMC knuckle. Weight reduction of $60 \%$ for the same model is shown in Table 6 . This could make the suspension system more easily follow the road undulations. The weight reduction of $60 \%$ achieved in this study is much higher than that achieved by geometry optimization alone, which was only $12 \%$ [8].

Table 5. Steering knuckle fatigue testing details.

\begin{tabular}{clcc}
\hline S1. No. & Materials & Steering-arm force $(\mathrm{kN})$ & No. of cycles survived $\times 10^{6}$ \\
\hline 1 & Al-15 wt.\%TiC & 2.8 & 1.200 \\
2 & Ductile iron & 2.8 & 0.937 \\
3 & LM 6 Al alloy & 2,8 & 0.536 \\
\hline
\end{tabular}

Table 6. Steering knuckle weight reduction comparison.

\begin{tabular}{clccc}
\hline S1.No. & Materials & Density $\left(\mathrm{kg} / \mathrm{m}^{3}\right)$ & Mass $(\mathrm{kg})$ & \% Weight Reduction \\
\hline 1 & Ductile iron & 7200 & 3.5 & \\
2 & LM 6 Al alloy & 2700 & 1.2 & 66 \\
3 & Al-15\% TiC & 3300 & 1.4 & 60 \\
\hline
\end{tabular}

\section{CONCLUSIONS}

The multiaxial force acting on the suspension component knuckle was analyzed for three load cases. To study the effect of forces, a finite-element model of knuckle geometry was developed and analyzed for three materials: MMC, LM6 alloy and ductile iron. Further, the knuckle was optimized in the steering-arm region to improve the fatigue life. The results of multiaxial forces obtained for three load cases of cornering, acceleration and braking indicated that the magnitude of the force developed during braking is the largest one. A finite-element model was developed for the steering knuckle and three materials (MMC, LM6 alloy and ductile iron) were analyzed. It was found that the steering-arm region the critical area under cyclic load conditions. The failure region of the knuckle was optimized under operating load conditions and fatigue life increased. Experimental results show that titanium carbide-reinforced composite material could be a better material for knuckles than ductile iron and LM6 alloy. 


\section{ACKNOWLEDGEMENTS}

The authors would like to express their gratitude to Dr.Mahalingam College of Engineering and Technology Pollachi, India for funding this research work. We thank M/s Sakthi Auto Components Ltd., Erode, India for their technical support in carrying out the testing.

\section{REFERENCES}

[1] Adebisi AA, Maleque M, Rahman M. Metal matrix composite brake rotor: historical development and product life cycle analysis. International Journal of Automotive and Mechanical Engineering. 2011;4:471-80.

[2] Bhaskar HB, Sharief A. Effect of solutionizing on dry sliding wear of Al2024Beryl metal matrix composite. Journal of Mechanical Engineering and Sciences. 2012;3:281-90.

[3] Abu Bakar MH, Raja Abdullah RI, Md. Ali MA, Kasim MS, Sulaiman MA, Ahmad SSN, et al. Surface integrity of LM6 aluminum metal matrix composite when machined with high speed steel and uncoated carbide cutting tools. Journal of Mechanical Engineering and Sciences. 2014;6:854-62.

[4] Chawla KK. Metal matrix composites: Wiley Online Library; 2006.

[5] Azrulhisham E, Asri Y, Dzuraidah A, Nik Abdullah N, Shahrum A, Che Hassan C. Evaluation of fatigue life reliability of steering knuckle using pearson parametric distribution model. International Journal of Quality, Statistics, and Reliability. 2011;2010.

[6] Kamal M, Rahman M, Rahman A. Fatigue life evaluation of suspension knuckle using multi body simulation technique. Journal of Mechanical Engineering Sciences. 2012;3:291-300.

[7] Zoroufi M, Fatemi A. Experimental durability assessment and life prediction of vehicle suspension components: a case study of steering knuckles. Proceedings of the Institution of Mechanical Engineers, Part D: Journal of Automobile Engineering. 2006;220:1565-79.

[8] Fatemi A, Shamsaei N. Multiaxial fatigue: An overview and some approximation models for life estimation. International Journal of Fatigue. 2011;33:948-58.

[9] Rahman MM, Ariffin AK, Rejab MRM, Kadirgama K, Noor MM. Multiaxial fatigue behavior of cylinder head for a free piston linear engine. Journal of Applied Sciences. 2009;9:2725-34.

[10] Abdul Majid MS, Daud R, Afendi M, Amin NAM, Cheng EM, Gibson AG, et al. Stress-strain response modelling of glass fibre reinforced epoxy composite pipes under multiaxial loadings. Journal of Mechanical Engineering and Sciences. 2014;6:916-28.

[11] Kamal M, Rahman MM, Sani MSM. Application of multibody simulation for fatigue life estimation. International Journal of Automotive and Mechanical Engineering. 2013;7:912-23.

[12] Kamal M, Rahman MM. Finite Element-Based Fatigue Behaviour of Springs in Automobile Suspension. International Journal of Automotive and Mechanical Engineering. 2014;10:1910-9. 
[13] Triantafyllidis G, Antonopoulos A, Spiliotis A, Fedonos S, Repanis D. Fracture characteristics of fatigue failure of a vehicle's ductile iron steering knuckle. Journal of failure analysis and prevention. 2009;9:323-8.

[14] Vijayarangan S, Rajamanickam N, Sivananth V. Evaluation of metal matrix composite to replace spheroidal graphite iron for a critical component, steering knuckle. Materials \& Design. 2013;43:532-41.

[15] Jhala R, Kothari K, Khandare S. Geometry and size optimization for a steering knuckle with no change in attachment geometry by reducing production cost and weight. International JOurnal of Advanced Engineering \& Application. 2010;322-7.

[16] d'Ippolito R, Hack M, Donders S, Hermans L, Tzannetakis N, Vandepitte D. Improving the fatigue life of a vehicle knuckle with a reliability-based design optimization approach. Journal of Statistical Planning and Inference. 2009;139:1619-32.

[17] Eitssayeam S, Intatha U, Rujijanagul G, Pengpat K, Tunkasiri T. Structural and electrical properties characterization of $(1-\mathrm{x}) \mathrm{PbZr0}$. 52Ti0. 48O3-xBaFe0. 5Nb0. 5 O3 system. Applied Physics A. 2006;83:295-9. 